\title{
Study on the Adsorption Mechanism of Graphene Oxide by Calcareous Sand in South China Sea
}

\author{
Beifeng Lv $\mathbb{D},{ }^{1}$ Wenjie Yu $\mathbb{D},{ }^{1}$ Jiale Luo $\mathbb{D},{ }^{1}$ Biao Qian $\mathbb{D}^{2},{ }^{2}$ Mulugeta Belete Asefa $\mathbb{D}^{1},{ }^{1}$ \\ and $\mathrm{Na} \operatorname{Li}\left(\mathbb{D}^{1}\right.$ \\ ${ }^{1}$ School of Civil Engineering, Shaoxing University, Shaoxing, Zhejiang 312000, China \\ ${ }^{2}$ Tongchuang Engineering Design Co., Ltd., Shaoxing 312000, China \\ Correspondence should be addressed to Na Li; lina@usx.edu.cn
}

Received 5 September 2021; Revised 17 October 2021; Accepted 23 October 2021; Published 23 November 2021

Academic Editor: Eloy S. Sanz P rez

Copyright (c) 2021 Beifeng Lv et al. This is an open access article distributed under the Creative Commons Attribution License, which permits unrestricted use, distribution, and reproduction in any medium, provided the original work is properly cited.

\begin{abstract}
To remove graphene oxide from wastewater, we used batch experiments with calcareous sand to recover GO. The adsorption properties and mechanisms of GO by calcareous sand were investigated by different characterization techniques. In this paper, the relationship between the coagulation of $\mathrm{GO}$ on calcareous sand and $\mathrm{pH}$, calcareous sand content, GO initial concentration, and temperature was studied. The results show that calcareous sand can effectively adsorb GO from aqueous solution, the interaction of GO with calcareous sand achieved interaction equilibrium in $5 \mathrm{~h}$, and the adsorption of GO by calcareous sand strongly depends on $\mathrm{pH}$. The isotherm data fitted to a Langmuir equation. A possible mechanism can be expressed from FTIR, XRD, Raman spectra, SEM, EDS, TEM, AFM, and XPS results. The test results indicate that calcareous sand is a potentially recoverable GO material.
\end{abstract}

\section{Introduction}

In recent years, GO (graphene oxide) has gained unprecedented development due to its special structure and excellent physical and chemical properties $[1,2]$. As one of the most excellent derivatives of graphene, GO has a layered structure with the epoxy group and hydroxyl group on its surface [3, 4]. With the widespread production and use of GO, GO will inevitably be discharged into the environment as a pollutant during production, transportation, use, and disposal. However, GO has been found to be toxic. Under certain conditions, it can cause harm to the human skin [5], lungs [6], and cells [7]. Therefore, in order to prevent GO from flowing into the natural ecosystem, it is necessary to study how to remove GO. At present, the main way to remove GO is to use adsorptive agent to adsorb GO; for this purpose, various chemical, physical, and biological methods were used for wastewater treatment which includes filtration, advanced oxidation, flocculation and coagulation, catalysis, photo and chemical degradation, and adsorption. Due to low cost and easy operation, adsorption is the most appropriate and reasonable choice for the removal of organic pollutants and inorganic heavy metal ions from wastewater $[8,9]$. In existing studies, the main adsorbent for adsorbing GO is $\mathrm{LDH}$. Although it shows a high adsorption capacity for GO, its production process is complex $[10,11]$, and the adsorption efficiency is still to be further improved by the maturity of the technology. Calcareous sand is an accumulation of carbonate material fragments, usually from shell fragments and bone fragments of marine organisms, the calcium carbonate content exceeds $50 \%$ and is widely distributed in the South China Sea, the Red Sea, the western continental platform of Australia, and the Bass Strait, covering about $40 \%$ of the land-sea interface $[12,13]$. In recent years, calcareous soil has entered the field of adsorption of heavy metal ions $[14,15]$. The adsorption of $\mathrm{Cd}, \mathrm{Cu}, \mathrm{Fe}, \mathrm{Mn}, \mathrm{Ni}, \mathrm{Zn}$, and other heavy metal ions on calcareous soil is superior $[16,17]$. Among them, the adsorption effect of calcareous soil on zinc is particularly prominent, so that plants on the calcareous soil are generally deficient in zinc $[18,19]$, and 
as a result, the yield of crops on calcareous soils is greatly reduced. On the other hand, the general lack of zinc on crops will also cause the human body that depends on the grainbased diet to obtain the necessary zinc. Zinc is an indispensable trace element for the human body. Lack of zinc in the human body can cause a series of health problems, such as impaired body development, immune system, and brain function $[20,21]$. At the same time, many studies have shown that the adsorption process of heavy metal ions by calcareous soil is a spontaneous endothermic process, and the adsorption capacity will increase with the increase of temperature $[19,22]$. The description of the above study shows that calcareous soil has good adsorption capacity. However, the interaction between GO and calcareous sand has not been extensively studied systematically, calcareous sand is rich in calcium ions which can cause GO to solidify and thus adsorb to calcareous sand, and that the absorption of toxic GO from excess calcareous sand in the ocean, which could leak into the natural world, could not only make proper.

In this work, using calcareous sand from the South China Sea to explore its adsorption effect on GO under different $\mathrm{pH}$, calcareous sand content, GO concentration, and temperature conditions. The interaction between GO and calcareous sand and its role in GO removal have been conducted. The main objectives of this work contain the following aspects: (1) study the effects of $\mathrm{pH}$, calcareous sand content, GO concentration, and temperature on the removal of GO by calcareous sand. (2) Fit the adsorption isotherm and thermodynamics of calcareous sand to remove GO. (3) Characterize the interaction of GO with calcareous sand by using spectroscopic and morphologic (FT-IR, Raman spectra, XPS, EDS, XRD, SEM, TEM, AFM) analyses and elucidate its role in GO removal. The work is expected to provide the fundamental experimental data of calcareous sand in South China Sea used to eliminate carbon nanomaterials from aqueous solutions.

\section{Experimental Section}

2.1. Materials. The GO aqueous solution was obtained from Suzhou Tanfeng Technology Co., Ltd. The graphene oxide was a high-purity single-layer graphene oxide freeze-dried by an improved Hummer method. The calcareous sand is collected from the reefs of the South China Sea, white, size below $2 \mathrm{~mm}$. The minimum and maximum $v$ pore ratios $\left(e_{\min }\right.$ and $\left.e_{\max }\right)$ are 1.37 and 1.85 , respectively. Chemical analysis of calcareous contains $92.70 \%$ calcium, $3.94 \%$ magnesium, $1.82 \%$ strontium, $0.64 \%$ sodium, $0.54 \%$ phosphorus, $0.39 \%$ sulfur, and $0.27 \%$ aluminum.

2.2. Characterization. Using $\mathrm{CuK} \alpha$ radiation, the crystal structure of the absorber was checked by X-ray diffractometer (XRD, Empyrean). The functional groups were identified by Fourier transform infrared spectroscopy (FTIR, NEXUS), and the scanning range was $400-4000 \mathrm{~cm}^{-1}$. Raman spectra are detected by Laser Confocal Micro-Raman Spectroscopy form Horiba Jobin Yvon (Raman Lab RAM HR800), and the exciter is $532 \mathrm{~nm}$.
The surface morphology was observed on with scanning electron microscope (SEM, JSM-6360LV), atomic force microscope (AFM, SPA400), and transmission electron microscope (JEOL JEM-1011). Energy dispersive X-ray spectroscopy (EDS) was performed on (OXFORD) X-act to detect the change of elements. Thermo ESCALAB 250 uses a focused monochromatic $\mathrm{Al} \mathrm{Ka} \mathrm{X}$-ray source $(\mathrm{hm}=1486.6 \mathrm{eV})$ for X-ray photoelectron spectroscopy (XPS) analysis. The zeta potential value was obtained by Zetasizer (ZS90) from Malvern Instruments.

2.3. Methods. The effect of certain factors, such as GO initial concentration $60 \mathrm{mg} / \mathrm{L}$ a, calcareous sand content $50 \mathrm{mg}$, temperature $30-50^{\circ} \mathrm{C}$, and effects of $\mathrm{pH}$, contact time, calcareous sand content, and GO initial concentrations on GO removal, was studied. Perform bath experiments in duplicate and use average data to evaluate adsorption performance.

At the wavelength of $221 \mathrm{~nm}$, the absorbance after adsorption is obtained by UV-Vis spectrophotometer. The calculation formula is as follows: (Eqs. (1)-(3)) [9].

$$
\begin{gathered}
R=\frac{C_{0}-C_{\mathrm{e}}}{C_{0}} \times 100 \%, \\
q_{e}=\frac{\left(C_{0}-C_{e}\right) \times V}{m}, \\
K_{d}=\frac{q_{e}}{C_{e}},
\end{gathered}
$$

where $C_{0}\left(\mathrm{mg} \cdot \mathrm{L}^{-1}\right)$ is the initial GO concentration of simulated solution, $C_{e}(\mathrm{mg} / \mathrm{L})$ is the concentrations at equilibrium, $R(\%)$ is the adsorption rate of $\mathrm{GO}$ by calcareous sand, $q_{e}(\mathrm{mg} / \mathrm{g})$ is the adsorption capacity of GO by calcareous sand, $m(\mathrm{~g})$ is the content of calcareous sand, $V(\mathrm{~L})$ is the GO solution volume, $K_{d}$ is the distribution coefficient.

The fitting formula of the adsorption isotherm (Langmuir, Freundlich and Temkin) model is as follows (Eqs. (4)-(6)) [23]:

$$
\begin{gathered}
\frac{1}{q_{e}}=\frac{1}{q_{m}}+\frac{1}{K_{L} \times q_{m}} \times \frac{1}{C_{e}}, \\
\ln \mathrm{q}_{e}=\ln \mathrm{K}_{F}+\frac{1}{n} \times \ln \mathrm{C}_{e}, \\
q_{e}=K_{T} \times \operatorname{lnf}+K_{T} \times \ln \mathrm{C}_{e},
\end{gathered}
$$

where $K_{L}$ is the adsorption equilibrium constant of Langmuir, $K_{F}$ is the adsorption equilibrium constant of Freundlich, and $K_{T}$ is the adsorption equilibrium constant of Temkin.

\section{Results and Discussion}

\subsection{Adsorption Property}

3.1.1. Effect of Time. To investigate the effect of contact time on GO condensation on calcareous sand, separate adsorption processes were performed using calcareous sand content $(50 \mathrm{mg}$ ) after different contact times (see Figure 1). 


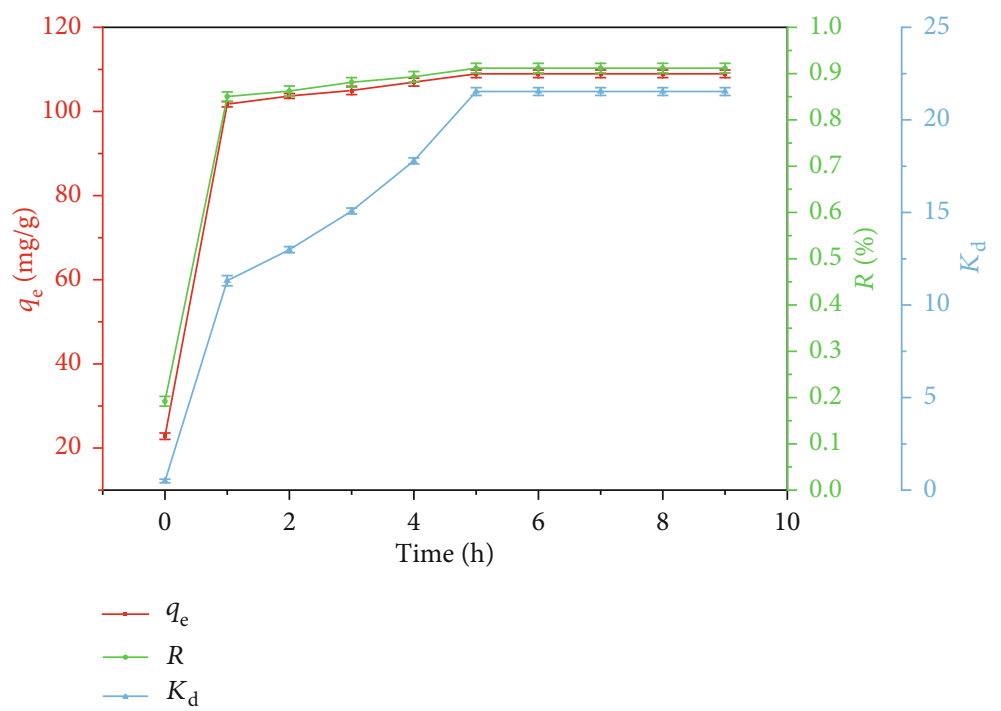

FIGURE 1: Effect of the contact time on GO adsorption on calcareous sand.

The adsorption curves clearly show that the deposition/ coagulation of GO on calcareous sand increases rapidly over a short period of time, reaches equilibrium after $5 \mathrm{~h}$, and then remains stable.

The GO removal rate increased from $20 \%$ to $92 \%$ within an increase in contact time from 0 to 5 hours, and the $q_{e}$ increases from $23 \mathrm{mg} / \mathrm{g}$ to $110 \mathrm{mg} / \mathrm{g} ; K_{d}$ is also an increase from 0.5 to 22 . At the initial contact time, the $\mathrm{Ca}^{2+}$ on the calcareous sand may play an important role in the adsorption of GO [24, 25], and the interaction between GO and calcareous sand is easy and rapid, thereby reducing the concentration of GO in the aqueous solution.

3.1.2. Effect of $p H$. $\mathrm{pH}$ has a great influence on adsorption $[26,27]$. The $\mathrm{pH}$ of the solution has a significant effect on the surface properties of the adsorbent [9], and $q_{e}, R$, and $K_{d}$ of GO on calcareous sand as a function of $\mathrm{pH}$ are shown in Figure 2(a). The zeta potential values of GO and calcareous sand/GO are also measured at different $\mathrm{pH}$ values, as shown in Figure 2(b). As shown in Figure 2(a), all the adsorption capacity, removal rate, and distribution coefficient of GO increase with increasing $\mathrm{pH}$ at $\mathrm{pH}<6$ and then decreasing quickly with $\mathrm{pH}$ increasing at $\mathrm{pH}>6$. The maximum adsorption capacity, removal rate, and distribution coefficient of GO by calcareous sand are $54.9 \mathrm{mg} / \mathrm{g}, 91.5 \%$, and 10.8, respectively. Slightly higher than the adsorption capacity of GO with iron tailings $(53.9 \mathrm{mg} / \mathrm{g})$ [28], it can be seen from the zeta potential diagram that the zeta values of $\mathrm{GO}$ and calcareous sand/GO are both negative values, both of which are electrostatic repulsion; so, the adsorption that occurs in this process may be chemical adsorption, that is, in the oxygen-containing functional groups on the surface of GO and the hydrogen bonding and Lewis acid-base interaction in calcareous sand [29], the hydroxyl group on the surface of calcareous sand can be regarded as Lewis base, and the delocalized $\pi$ electron on the surface of GO can be regarded as Lewis acid.
As shown in Figure 2(b), when the $\mathrm{pH}$ is less than 5, the potential difference between GO and calcareous sand becomes smaller, indicating that the electrostatic repulsion between the two is decreasing, indicating that the hydrogen bond and Lewis acid-base interaction between GO and calcareous sand are relatively increasing. For the increase in adsorption capacity, however, when the $\mathrm{pH}$ is greater than 5 , the potential difference gradually becomes larger; that is, the electrostatic repulsion between GO and calcareous sand is greater than the hydrogen bond and the Lewis acid-base effect, making the adsorption capacity weaker.

3.1.3. Effect of Calcareous Sand Content. Figure 2(c) presents the influence of $m$ on the $q_{e}, R$, and $K_{d}$ of the GO adsorption. The result will provide an opportunity to expect less adsorbent consumption or higher adsorption efficiency. With the calcareous sand content increasing from $30 \mathrm{mg}$ to $70 \mathrm{mg}$, removal rate and distribution coefficient of GO increase gradually, tending to $94 \%$ and 12.8 , respectively. This is because as the content of calcareous sand increases, the $\mathrm{Ca}$ in calcareous sands also increases. However, the adsorption capacity of GO decreased. The adsorption capacity of calcareous sand for GO decreased. This is because increasing the content of calcareous sand under the premise of maintaining the $\mathrm{GO}$ concentration of $60 \mathrm{mg} / \mathrm{L}$, resulting in a decrease in the adsorption capacity of calcareous sand per unit. This shows that we need to reasonably choose high removal rate (low residue) or high adsorption capacity (low adsorbent consumption) according to the actual application. [30]. In this study, $70 \mathrm{mg}$ of calcareous sand was taken as an example for follow-up experiments.

3.1.4. Effect of GO Initial Concentration. The removal of GO on calcareous sand was studied with different $C_{0}$ of 80,100 , 120,140 , and $160 \mathrm{mg} / \mathrm{L}$, respectively. Figure $2(\mathrm{~d})$ shows that the $R$ is influenced by GO initial concentrations. It can be seen from Figure 2(d) that as the initial concentration of GO increases, the adsorption capacity of calcareous sand on GO increases, and the maximum can reach $103 \mathrm{mg} / \mathrm{g}$, 


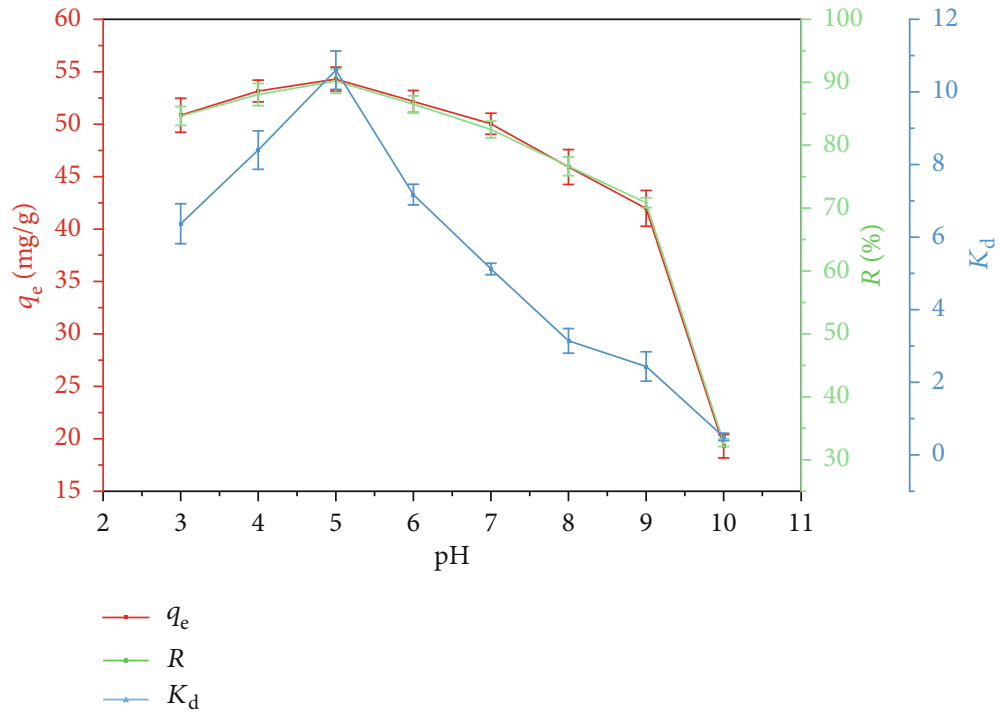

(a)

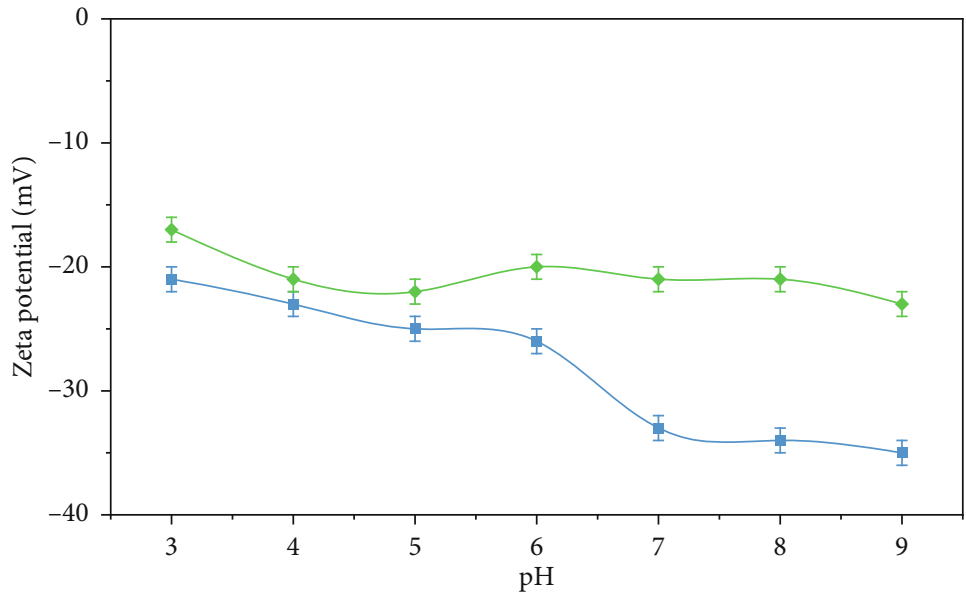

- $\mathrm{GO}$

$\rightarrow-\mathrm{GO} /$ Calcareous sand

(b)

Figure 2: Continued. 


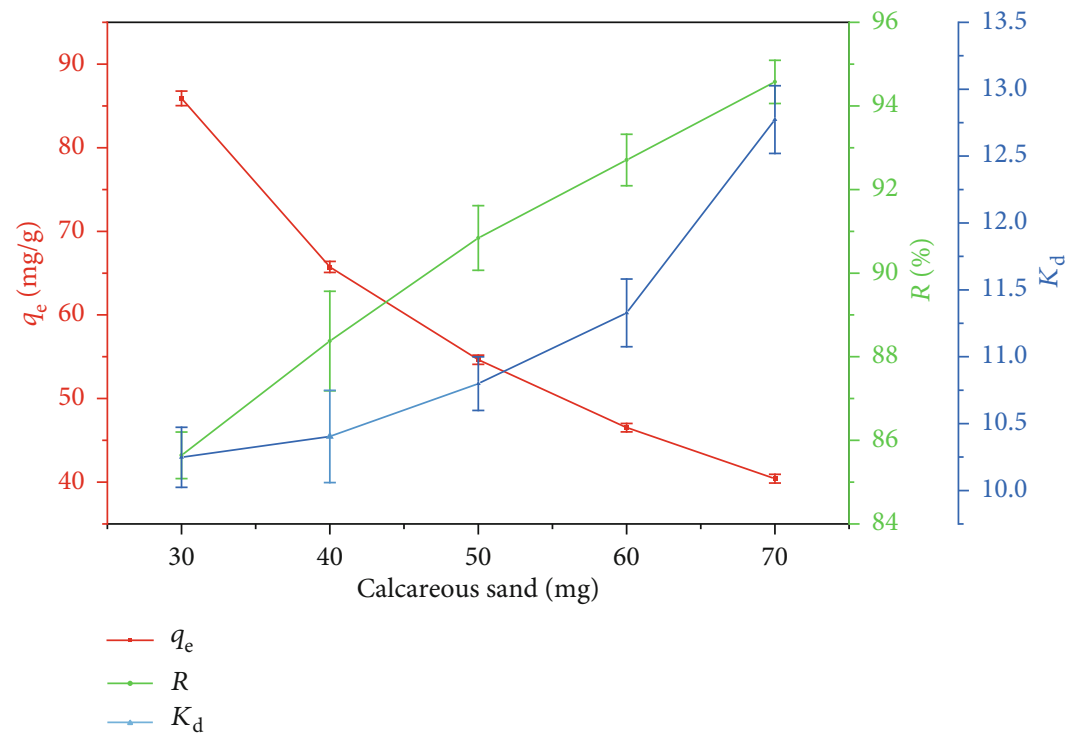

(c)

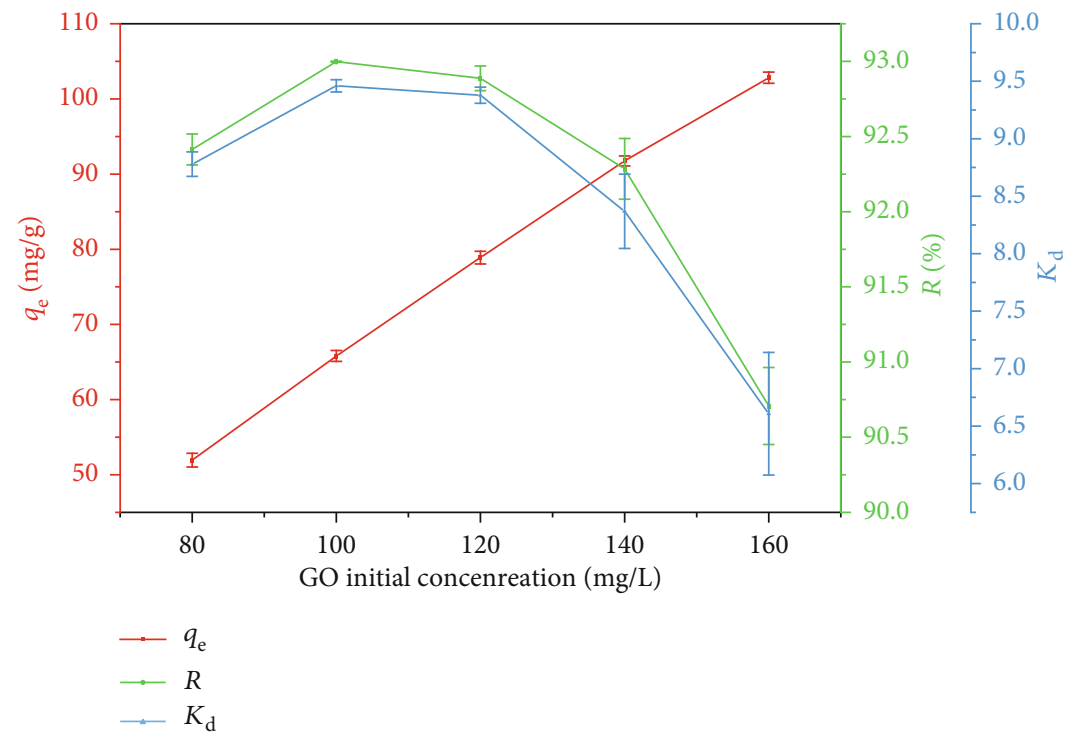

(d)

FIGURE 2: Adsorption of GO on calcareous (a) effect of pH. (b) Zeta potentials of GO and calcareous sand/GO. (c) Effect of calcareous sand content. (d) GO initial concentration.

but the removal rate and distribution coefficient reach 100 $\mathrm{gm} / \mathrm{L}$ at the initial concentration of GO; it began to decline afterwards, which may be due to the fact that calcareous sand has not yet reached saturation at a lower initial GO concentration, and the limited available calcareous sand quickly saturates at a higher initial GO concentration. [31]. Therefore, the initial GO concentration of $100 \mathrm{mg} / \mathrm{L}$ is the saturation point of calcareous sand adsorption.

\subsection{Adsorption Isotherm and Thermodynamic Study}

3.2.1. Adsorption Isotherm. Figure 3 shows the adsorption isotherm of go on calcareous sand. The fitting results of Langmuir model, Freundlich model, and Temkin model are shown in Table 1. It can be seen that with the increase of temperature, the adsorption capacity of calcareous sand on go gradually increases, and the maximum adsorption capacity calculated from different isotherms increases with the increase of temperature, indicating that the increase of temperature helps to improve the maximum adsorption capacity. It can be seen from Table 1 that the data show that for the adsorption of go on calcareous sand, the relevant parameters fitted by Langmuir model are higher; that is, Langmuir model is more suitable for the process. Therefore, we speculate that the adsorption of go on calcareous sand is mainly monolayer adsorption, and there is no lateral effect or steric hindrance between the adsorbed molecules and adjacent points, and the combination of GO and calcareous sand surface is driven by physical force and all positions equivalent in energy and the same affinity to $\mathrm{GO}[32,33]$. 


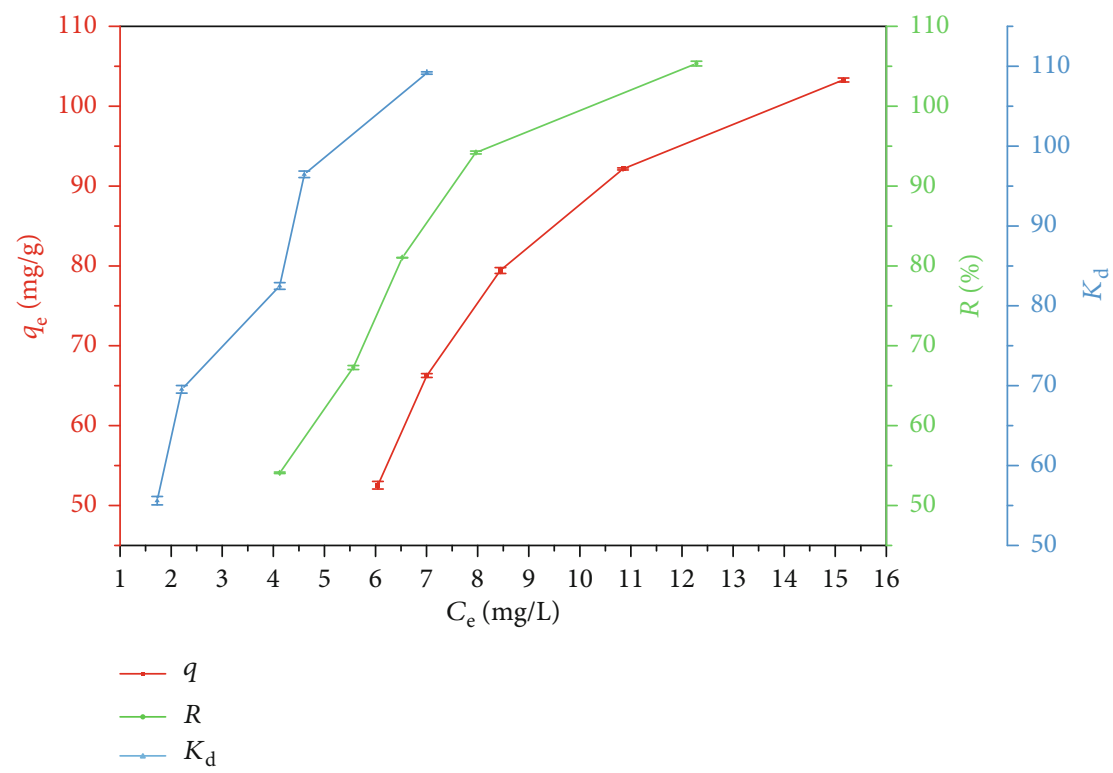

(a)

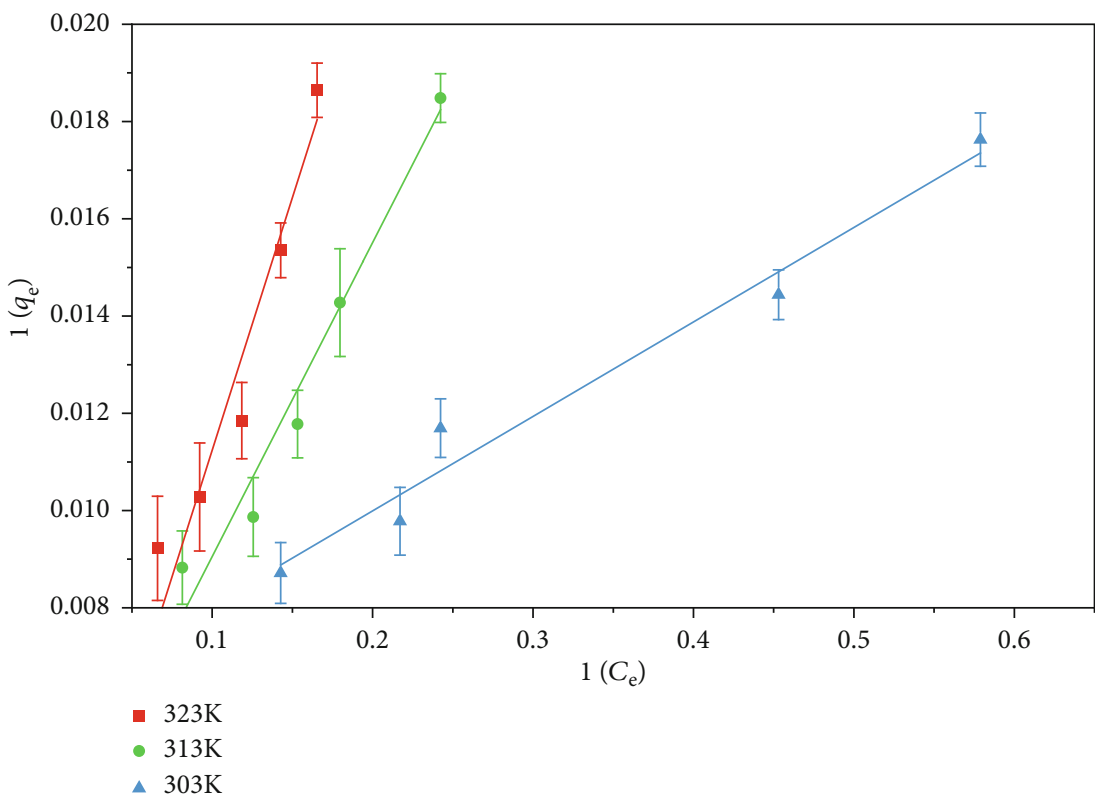

(b)

FIgUre 3: Continued. 




- $301 \mathrm{~K}$
- $313 \mathrm{~K}$
- $323 \mathrm{~K}$

(c)

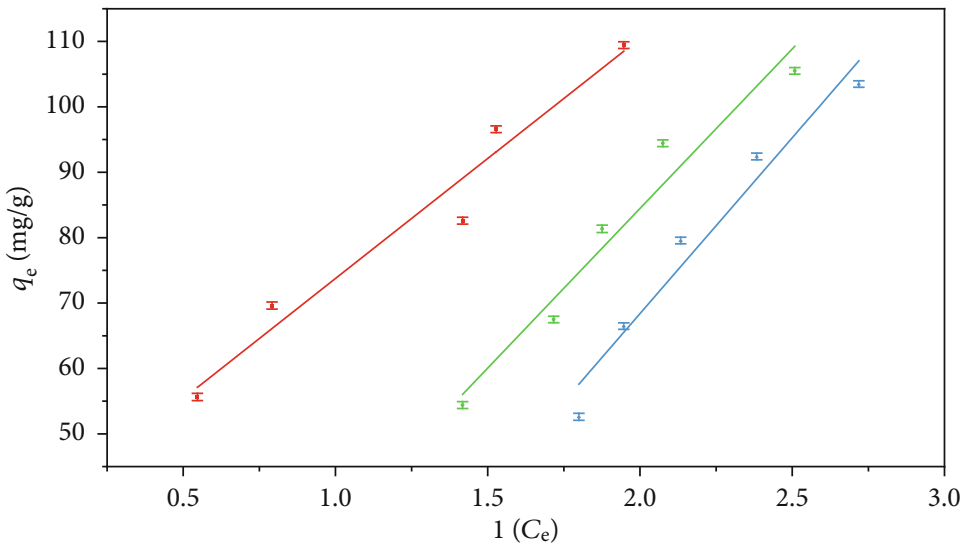

$\Delta 301 \mathrm{~K}$

- $313 \mathrm{~K}$

- $323 \mathrm{~K}$

(d)

Figure 3: (a) Adsorption isotherms of GO on calcareous sand at $T=303 \mathrm{~K}, 313 \mathrm{~K}$, and $323 \mathrm{~K}$. Equilibrium adsorption isotherms fitted by (b) Langmuir model, (c) Freundlich model, and (d) Temkin model.

TABLE 1: Adsorption isotherm models parameters.

\begin{tabular}{|c|c|c|c|c|c|c|c|c|c|c|}
\hline \multirow{2}{*}{\multicolumn{2}{|c|}{$\begin{array}{l}\text { Model } \\
\text { parameters }\end{array}$}} & \multicolumn{3}{|c|}{ Langmuir } & \multicolumn{3}{|c|}{ Freundlich } & \multicolumn{3}{|c|}{ Temkin } \\
\hline & & $\begin{array}{c}q_{m} \\
(\mathrm{mg} / \mathrm{g})\end{array}$ & $\begin{array}{c}K_{L} \\
(\mathrm{~L} / \mathrm{mg})\end{array}$ & $R^{2}$ & $1 / n$ & $K_{F}$ & $R^{2}$ & $K_{T}(\mathrm{~L} / \mathrm{mg})$ & $f$ & $R^{2}$ \\
\hline \multirow{3}{*}{$T / K$} & 303 & 357.14 & 0.00 & 0.93 & 0.70 & 16.49 & 0.96 & 54.04 & 0.48 & 0.96 \\
\hline & 313 & 250.00 & 0.07 & 0.97 & 0.63 & 23.49 & 0.93 & 49.11 & 0.76 & 0.96 \\
\hline & 323 & 149.25 & 0.36 & 0.96 & 0.46 & 45.73 & 0.92 & 36.41 & 2.8 & 0.96 \\
\hline
\end{tabular}

The Temkin model can also be fitted linearly to evaluate adsorption systems with heterogeneous surfaces. The correlation coefficient is as high as 0.96 , indicating that the change of adsorption heat with adsorption capacity is not exponential, but linear energy $[34,35]$. This may be due to the strong chemical bond interaction between GO and calcareous sand adsorbent.
3.2.2. Adsorption Thermodynamic. The temperature is a significant parameter for the adsorption process [36]. Figure 4 shows the effect of temperature on the removal of GO by calcareous sand. Obviously, the removal of GO by calcareous sand was more favorable at higher temperature. The thermodynamic parameters of the adsorption process, i.e., the values of standard Gibbs free energy $\left(\Delta G^{\circ}\right)$, standard 


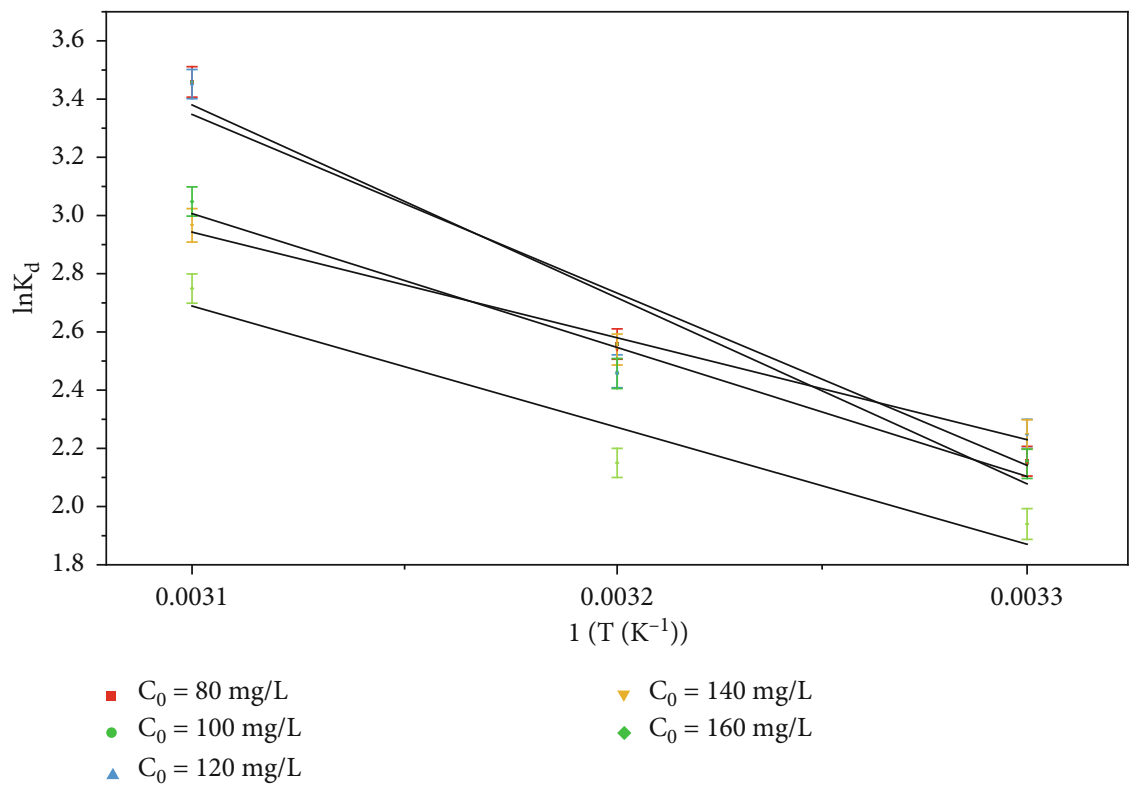

FIgURE 4: Linear relationship between $\ln \mathrm{K}_{d}$ and $1 / T(K-1)$ adsorbed by GO on calcareous sand.

TABLE 2: Adsorption thermodynamic parameters.

\begin{tabular}{|c|c|c|c|c|c|c|}
\hline \multirow{2}{*}{ Adsorbate } & \multirow{2}{*}{$\begin{array}{c}C_{0} \\
(\mathrm{mg} / \mathrm{L})\end{array}$} & \multirow{2}{*}{$\begin{array}{c}\Delta H^{\circ} \\
(\mathrm{kJ} / \mathrm{Mol})\end{array}$} & \multirow{2}{*}{$\begin{array}{c}\Delta S^{\circ} \\
(\mathrm{kJ} / \mathrm{Mol})\end{array}$} & \multicolumn{3}{|c|}{$\Delta G^{\circ}(\mathrm{kJ} / \mathrm{Mol})$} \\
\hline & & & & $303 \mathrm{~K}$ & $313 \mathrm{~K}$ & $323 \mathrm{~K}$ \\
\hline \multirow{5}{*}{ Calcareous sand } & 80 & 53.05 & 0.19 & -5.24 & -7.16 & -9.09 \\
\hline & 100 & 48.71 & 0.18 & -5.36 & -7.14 & -8.93 \\
\hline & 120 & 30.58 & 0.12 & -5.56 & -6.75 & -7.94 \\
\hline & 140 & 36.64 & 0.14 & -5.28 & -6.66 & -8.05 \\
\hline & 160 & 33.48 & 0.13 & -4.67 & -5.93 & -7.19 \\
\hline
\end{tabular}

enthalpy $\left(\Delta H^{\circ}\right)$, and standard entropy $\left(\Delta S^{\circ}\right)$, are calculated by the following formulas (Eqs. (7) and (8)) [24]:

$$
\begin{gathered}
\ln K_{d}=-\frac{\triangle H^{\circ}}{R} \times \frac{1}{T}+\frac{\triangle S^{\circ}}{R}, \\
\ln K_{d}=-\frac{\triangle H^{\circ}}{R} \times \frac{1}{T}+\frac{\triangle S^{\circ}}{R},
\end{gathered}
$$

where $T$ is the Kelvin absolute temperature, and $R$ is the ideal gas constant, usually $8.314 \mathrm{~J} /(\mathrm{mol} \cdot \mathrm{K})) . \Delta H^{\circ}$ can reflect whether the adsorption process is endothermic or exothermic, $\Delta S^{\circ}$ represents whether the adsorption is entropy increase or entropy decrease, and $\Delta G^{\circ}$ reflects whether the adsorption is spontaneous. The thermodynamic parameters are summarized in Table $2, \Delta G^{\circ}$ is a negative value, indicating that the adsorption reaction of GO on calcareous sand is a spontaneous process; $\Delta H^{\circ}$ is a positive value, indicating that the adsorption of GO on calcareous sand is an endothermic process. The positive value may be due to the formation of new chemical bonds during the adsorption process, resulting in changes in the original structure [37, 38]. Thermodynamic studies show that the adsorption of GO on calcareous sand is a spontaneous endothermic reaction.

\section{Adsorption Mechanism}

The mechanism of GO adsorption on calcareous sand was discussed from the FT-IR, XRD, Raman spectrum, SEM, TEM, AFM, and XPS analysis. The FT-IR spectra can effectively analyze the characterization of surface functional groups of GO adsorbed on calcareous sand [11]. As shown in Figure 5(a), the bands at approximately $3413 \mathrm{~cm}^{-1}$ are caused by the stretching vibrations of lattice water and -OH groups and $1612 \mathrm{~cm}^{-1}$ assigned to the $\mathrm{H}-\mathrm{O}-\mathrm{H}$ stretching and bending vibrations, respectively [39]. Comparing the spectra of GO, calcareous sand, and calcareous sand/ GO after adsorption, the spectra of calcareous sand/GO are closer to those of calcareous sand, and the functional group does not change much, indicating that the surface of the adsorbed material is more covered by calcareous sand.

The obtained XRD patterns have overwhelming support for estimating the structure of the adsorbent before and after adsorption [40]. The XRD patterns of GO, calcareous sand, and calcareous sand/GO are shown in Figure 5(b). From Figure 5(b), we can see that the typical peaks of calcareous sand/GO after adsorption are basically the same as those of calcareous sand before adsorption, which indicates that the structure of calcareous sand will not be destroyed after GO adsorption [41], and it is also consistent with the FT-IR test 


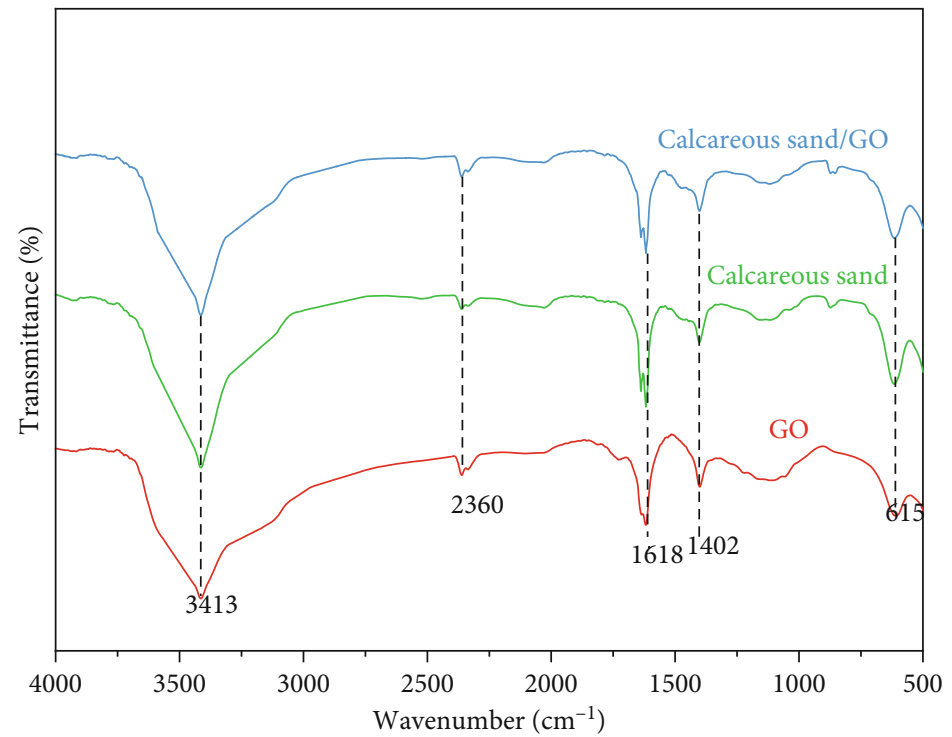

(a)

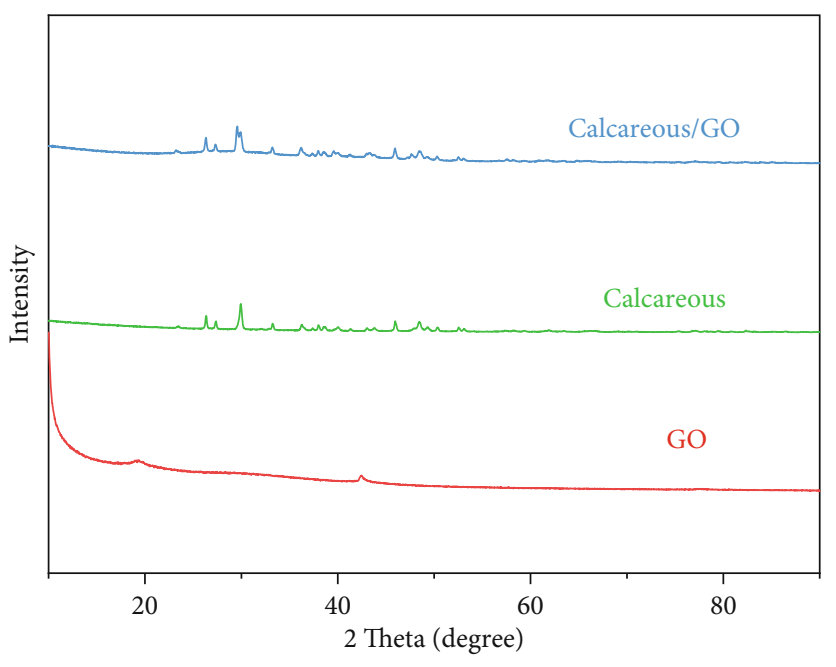

(b)

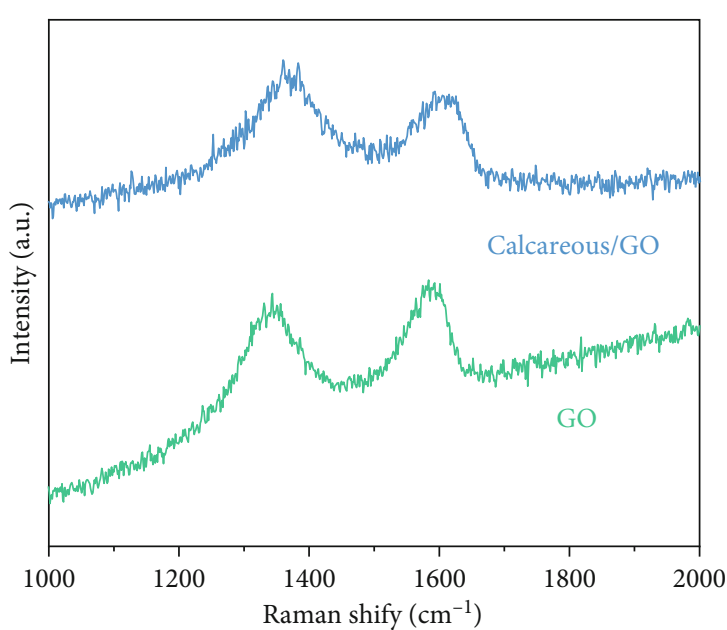

(c)

FIGURE 5: FT-IR spectra of GO, calcareous sand, and calcareous sand/GO (a); XRD patterns of GO, calcareous sand, and calcareous sand/ GO (b); and Raman spectra of GO and calcareous sand/GO (c).

results. Most of the material obtained after calcareous sand adsorbs GO that is calcareous sand or calcareous sand adheres to GO.

Raman spectroscopy is used to study the degree of order on the surface of adsorption composites [42, 43]. Figure 5(c) shows the Raman spectrum of calcareous sand/GO obtained by the adsorption of GO and calcareous sand. There are two distinct characteristic peaks of $\mathrm{GO}$ at $1350 \mathrm{~cm}^{-1}$ and $1580 \mathrm{~cm}^{-1}$ [44, 45], which are consistent with the $\mathrm{D}$ band and $\mathrm{G}$ band reported in the literature. The $\mathrm{D}$ band originates from the stretching vibration of the $\mathrm{sp}^{3}$ carbon atom, causing defects and misalignment, while the $\mathrm{G}$ band originates from the stretching vibration of the $\mathrm{sp}^{2}$ carbon atom, which corresponds to the first-order scattering of the $E_{2 g}$ mode [46]. The peak position of calcareous sand has shifted after the adsorption of GO, and after the adsorption occurs, the relative intensity ratio (ID/IG) increased significantly and disorderly increased. This conclusion is also consistent with the FT-IR and XRD test results.

The morphologies and structure of adsorption materials are shown in Figure 6. The surface morphology of GO was studied by TEM and SEM, and the images are shown in Figures 6(a) and 6(d). The SEM and TEM images of GO show a characteristic two-dimensional structure with many wrinkles, which is the typical morphology of GO reported in many preliminary works [47]. It can be seen from Figure 6(b) that calcareous sand is needle-like and platelike crystal grains, with many cavities on its surface and inside $[48,49]$; so, it is conducive to its adsorption of GO. Observe the SEM figure (Figure 6(c)) of the substance obtained after the calcareous sand adsorbs GO, and the surface becomes flat, indicating that the calcareous sand with many holes on the surface is filled by GO after the adsorption. Meanwhile, it can be seen from Figures 6(d) and 6(e) 


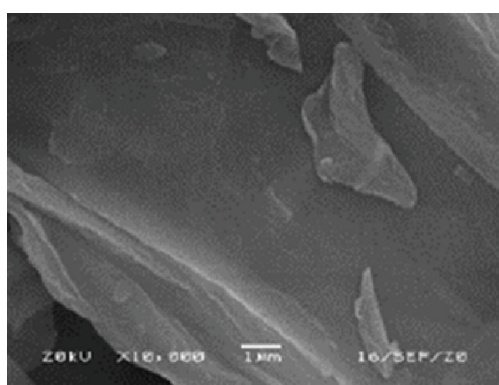

(a)

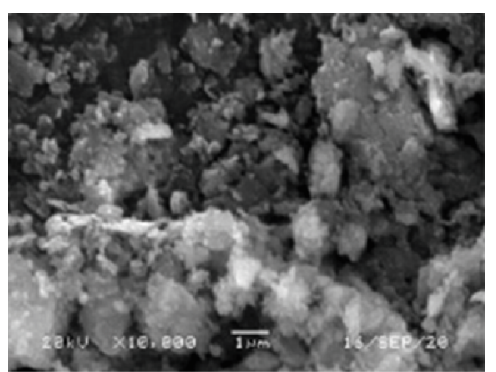

(b)

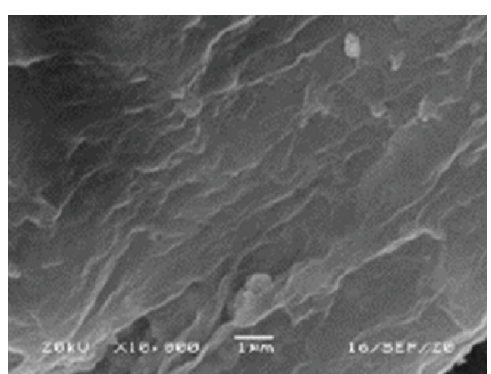

(c)

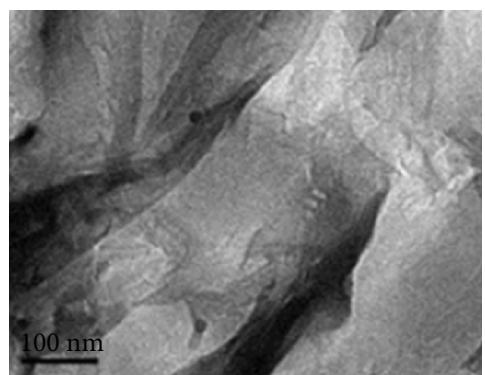

(d)

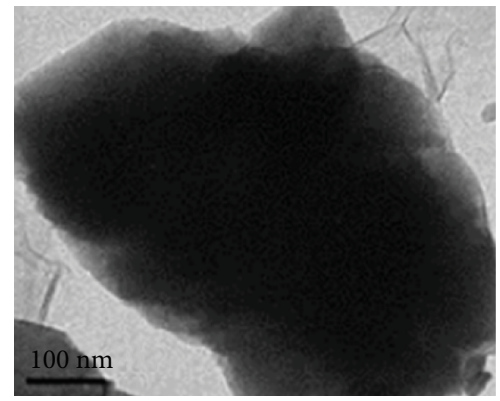

(e)

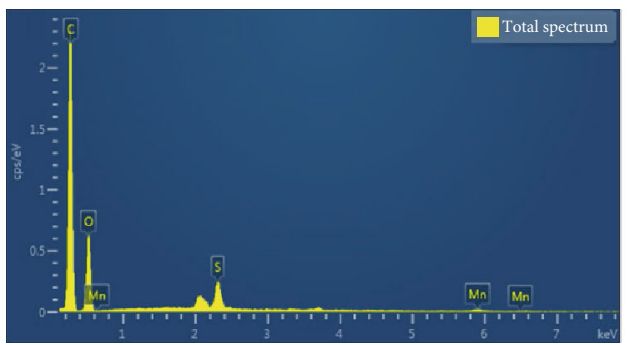

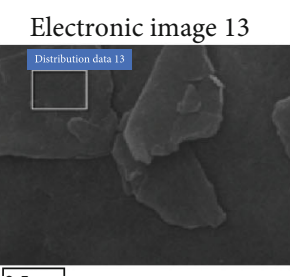

$2.5 \mu \mathrm{m}$

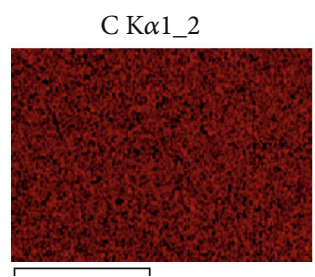

$1 \mu \mathrm{m}$

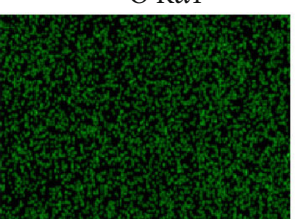

$1 \mu \mathrm{m}$

(f)

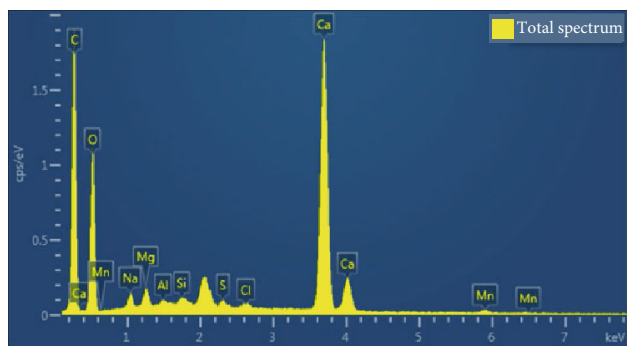

Electronic image 1

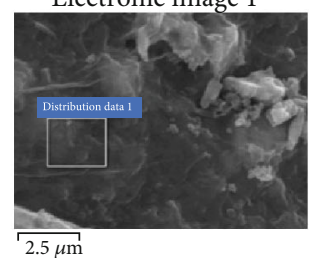

C K $\alpha 1 \_2$

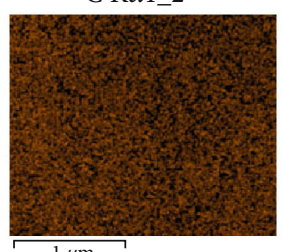

$1 \mu \mathrm{m}$

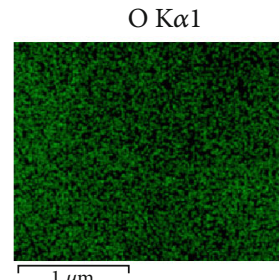

(g)

Figure 6: Continued. 

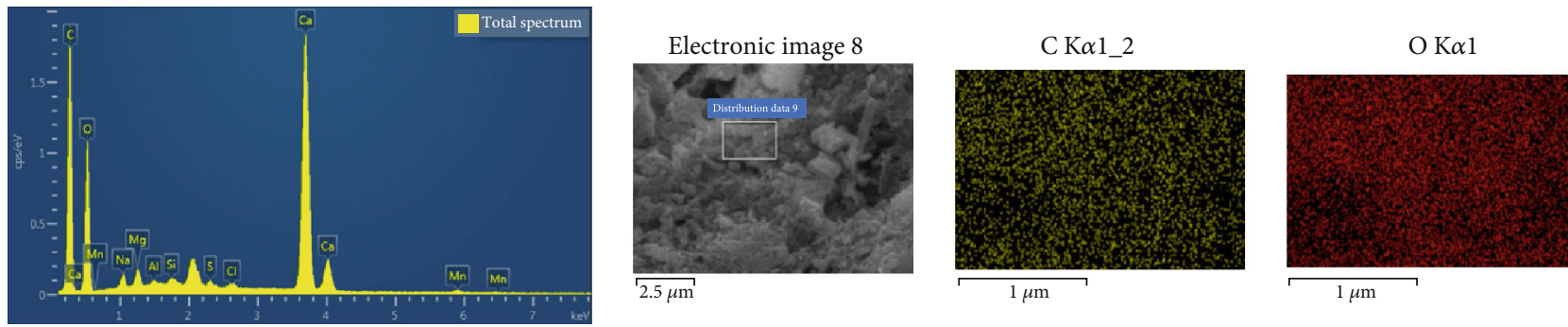

(h)

FIGURE 6: SEM images of GO (a), calcareous sand (b), and calcareous sand/GO (c). TEM images of GO (d) and calcareous sand/GO (e), EDS images of GO (f), calcareous sand (g) and calcareous sand/GO (h).
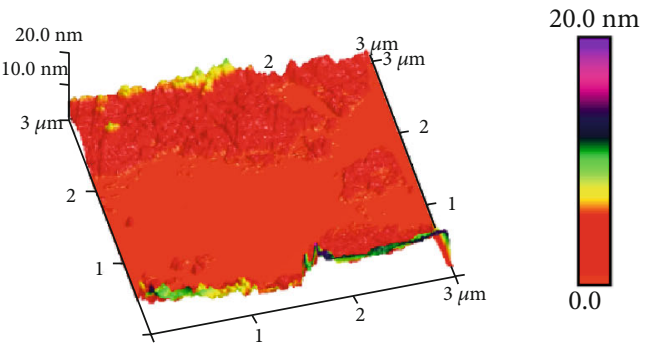

Height sensor
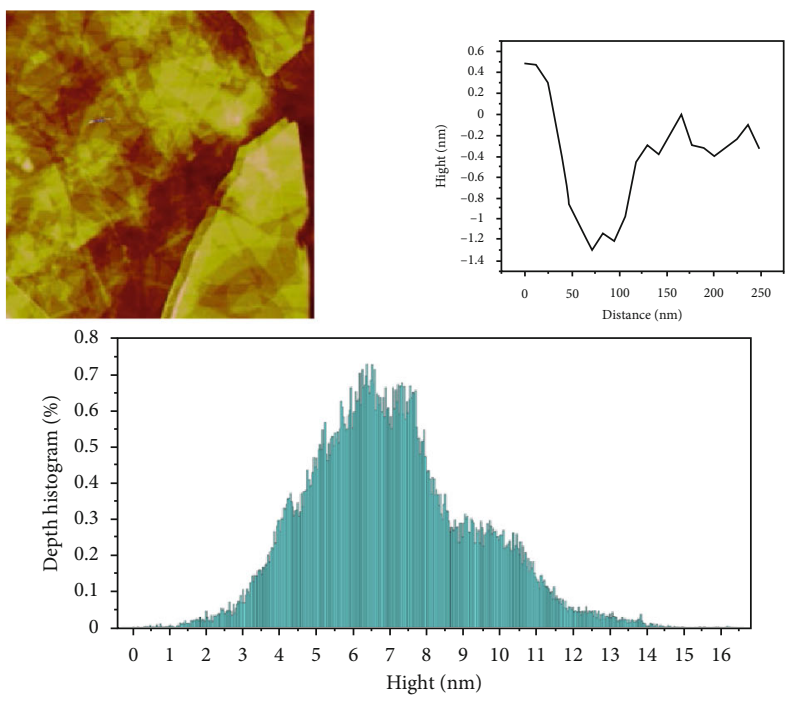

(a)

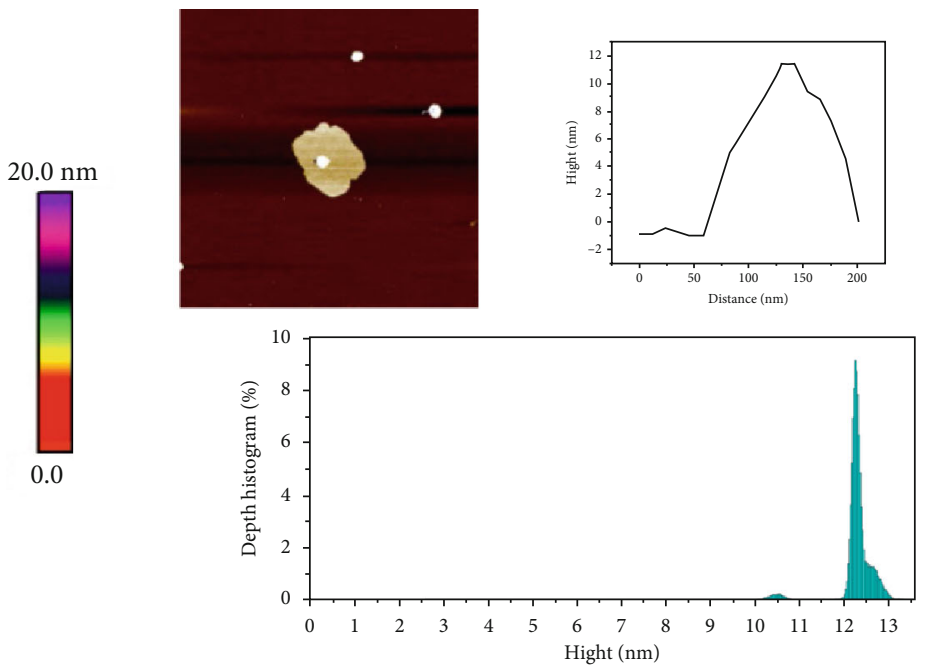

(b)

Figure 7: AFM image of GO (a) and calcareous sand/GO (b).

that the surface morphology of GO changed obviously after adsorption, and a lot of black substances were attached to the surface; so, it can be inferred that calcareous sand has adsorbed GO. In order to further verify that calcareous sand adsorbs GO and the two are fused with each other, the chemical composition of the material before and after adsorption is analyzed by EDS test; the test results are shown in Figures 6(f)-6(h). The result of EDS shows that the content of $\mathrm{C}$ and $\mathrm{O}$ elements on calcareous sand increases, indicating that GO is in calcareous sand. 


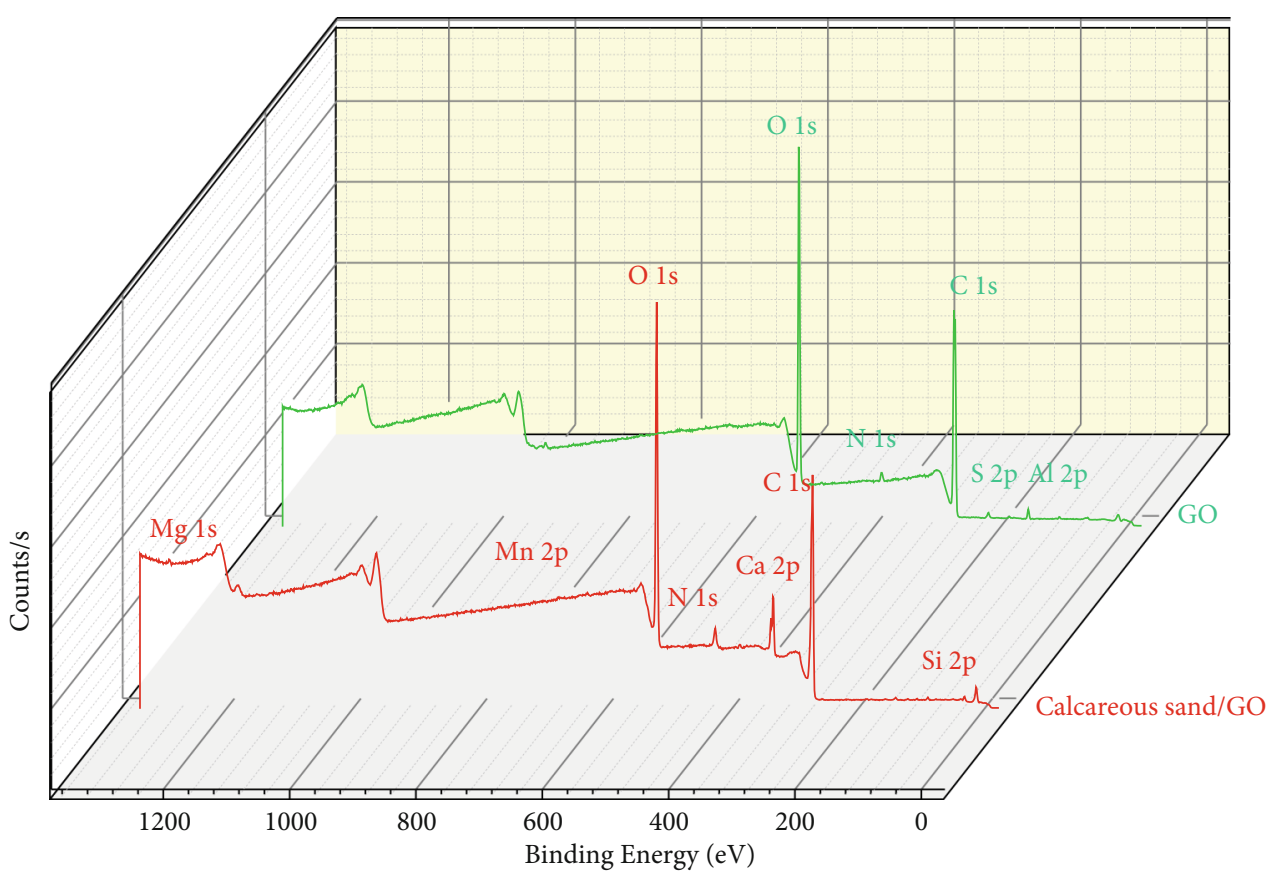

(a)

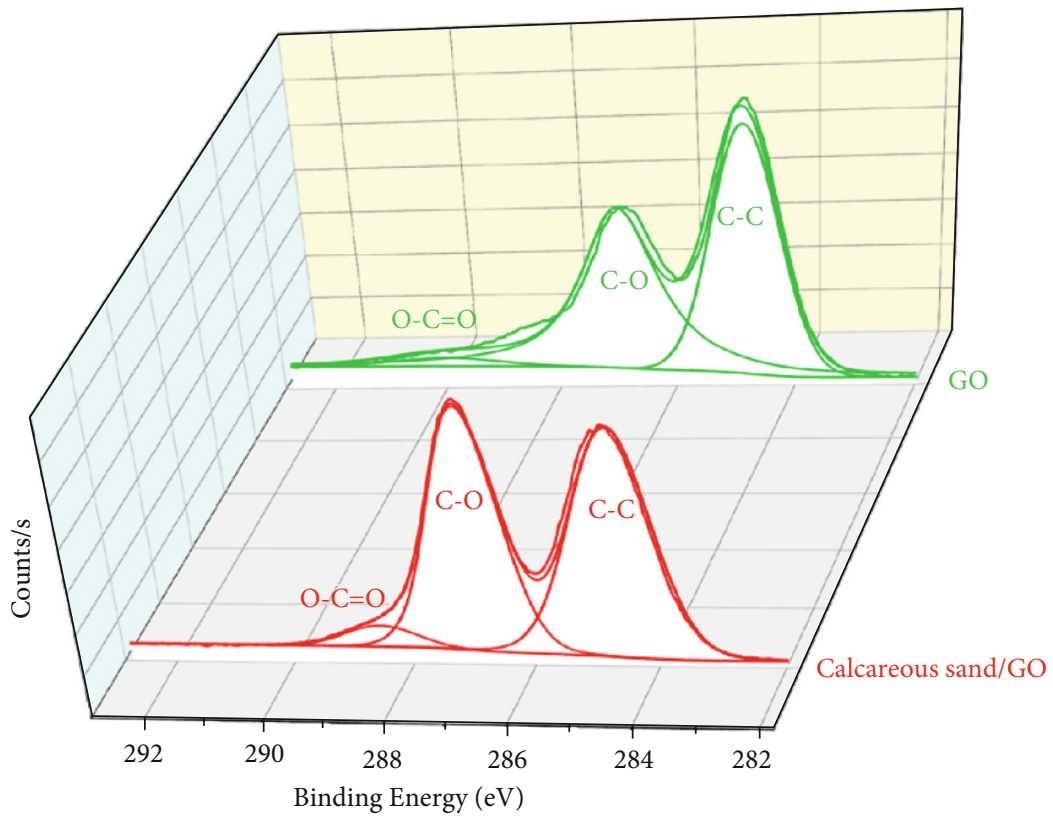

(b)

Figure 8: XPS spectra (a). The high C $1 \mathrm{~s}$ deconvolution (b).

AFM analysis provides an effective method for characterizing the microstructure [50]. Figure 7 shows the AFM images of GO and calcareous sand/GO. The AFM micrograph and height profile of the synthesized GO are shown in Figure $7(\mathrm{a})$. it is found that the thickness of GO is about $0.5 \mathrm{~nm}$, and the thickness of the calcareous sand/GO after adsorption is close to $12 \mathrm{~nm}$, indicating that the thickness of the adsorbed material increases after adsorption, which is consistent with the results in SEM and TEM images. However, the surface of calcareous sand has become smoother. This may be because the GO has adsorbed and gathered to a point. This can also be verified from the height distribution map. The height distribution of GO is more concentrated around $7 \mathrm{~nm}$, while the calcareous sand/GO is less concentrated around $12 \mathrm{~nm}$.

XPS was used to further analyze the GO adsorption mechanism of calcareous sand. As shown in Figure 8(a), the peaks for $\mathrm{N} 1 \mathrm{~s}, \mathrm{C} 1 \mathrm{~s}$, and $\mathrm{O} 1 \mathrm{~s}$ are all observed for GO before and after adsorption. It can be observed that the strength of $\mathrm{C} 1 \mathrm{~s}$ peak enhances after GO coagulation, indicating the strong adsorption of $\mathrm{GO}$ on calcareous sand [26]. The high deconvolution of C $1 \mathrm{~s}$ spectrum before and 
GO adsorption is shown in Figure 8(b) and observes that the C $1 \mathrm{~s}$ spectrum before GO is adsorbed; it can be deconvoluted into three components at 284.7, 287.0, and $288.5 \mathrm{eV}$ [51-53], which are assigned to $\mathrm{C}-\mathrm{C}, \mathrm{C}-\mathrm{O}$, and $\mathrm{O}-\mathrm{C}=\mathrm{O}$ groups, respectively. However, after $\mathrm{GO}$ is adsorbed by calcareous sand, the area for the peak assigned to $\mathrm{O}-\mathrm{C}=\mathrm{O}$ increases, and the peak position of $\mathrm{O}-\mathrm{C}=\mathrm{O}$ changes from $288.5 \mathrm{eV}$ to $290.0 \mathrm{eV}$. The change of the area and position of $\mathrm{O}-\mathrm{C}=\mathrm{O}$ shows that the interaction of $\mathrm{GO}$ with calcareous sand is conducted by $\mathrm{O}-\mathrm{C}=\mathrm{O}$ in the adsorption process [54]. It can be seen from the above analysis that GO can be effectively removed by adsorbing go on the surface of calcareous sand.

\section{Conclusion}

The interaction between GO and calcareous sand was systematically studied by adsorbing GO on calcareous sand. The interaction between GO and calcareous sand was studied by the combination of adsorption test and micromorphology characterization. The results show that the contact time, $\mathrm{pH}$ content, and initial concentration of GO will affect the adsorption process of $\mathrm{GO}$ adsorbed by calcareous sand. The adsorption capacity of GO by calcareous sand first increases and then decreases with the increase of $\mathrm{pH}$ and decreases with the increase of calcareous sand content, but increases with the increase of initial concentration of GO. Through microscopic characterization, it was found that after calcareous sand adsorbed GO, GO attached to the surface of calcareous sand, and the adsorption process was accompanied by the change of functional groups. The results show that GO is easy to interact with calcareous sand, thus affecting its environmental behavior.

At the same time, calcareous sand is widely used as a construction material [55], and it is therefore foreseeable that the addition of calcareous sand as a construction material in the construction of GO contaminated sites could also adsorb GO from contaminated sites to avoid GO harming human health through the water cycle, indicating that the adsorption potential of calcareous sand for GO is very high.

\section{Data Availability}

The data used to support the findings of this study are included within the article.

\section{Conflicts of Interest}

The authors declare that they have no known competing financial interests or personal relationships that could have appeared to influence the work reported in this paper.

\section{Acknowledgments}

This research was funded by the National Natural Science Foundation of China (41772311), the National Natural Science Foundation of China (52179107), the Research Fund of Zhejiang Provincial Department of Housing and UrbanRural Development (2017K179, 2016K130), and International Scientific and Technological Cooperation Projects of Shaoxing University (2019LGGH1007).

\section{References}

[1] Y. Gao, X. Ren, G. Song, D. Chen, X. Zhang, and C. Chen, "Colloidal properties and stability of uv-transformed graphene oxide in aqueous solutions: the role of disorder degree," Journal of Hazardous Materials, vol. 382, p. 121097, 2020.

[2] J. Wang, R. Ma, and P. C. Gu, "Chitosan modified silicon dioxide composites for the capture of graphene oxide," Journal of Physics and Chemistry of Solids, vol. 147, p. 109629, 2020.

[3] F. Mouhat, F. X. Coudert, and M. L. Bocquet, "Structure and chemistry of graphene oxide in liquid water from first principles," Nature Communications, vol. 11, no. 1, p. 1566, 2020.

[4] L. Valentini, S. Bittolo Bon, and G. Giorgi, "Engineering graphene oxide/water interface from first principles to experiments for electrostatic protective composites," Polymers (Basel), vol. 12, no. 7, p. 1596, 2020.

[5] Z. Peng, X. Liu, W. Zhang et al., "Advances in the application, toxicity and degradation of carbon nanomaterials in environment: a review," Environment International, vol. 134, p. 105298, 2020.

[6] L. Chen, J. Li, Z. Chen et al., "Toxicological evaluation of graphene-family nanomaterials," Journal of Nanoscience and Nanotechnology, vol. 20, no. 4, pp. 1993-2006, 2020.

[7] L. Hu, Y. Fu, L. Rong et al., "Evaluating the cytotoxicity of graphene oxide using embryonic stem cells-derived cells," Journal of Biomedical Materials Research Part A, vol. 108, no. 6, pp. 1321-1328, 2020.

[8] S. Pandey, E. Fosso-Kankeu, J. Redelinghuys, J. Kim, and M. Kang, "Implication of biofilms in the sustainability of acid mine drainage and metal dispersion near coal tailings," Science of The Total Environment, vol. 788, article 147851, 2021.

[9] M. A. Khapre, S. Pandey, and R. M. Jugade, "Glutaraldehydecross-linked chitosan-alginate composite for organic dyes removal from aqueous solutions," International Journal of Biological Macromolecules, vol. 190, pp. 862-875, 2021.

[10] Y. Zou, X. Wang, Y. Ai et al., "Coagulation behavior of graphene oxide on nanocrystallined mg/al layered double hydroxides: batch experimental and theoretical calculation study," Environmental Science \& Technology, vol. 50, no. 7, pp. 3658-3667, 2016.

[11] J. Wang, X. X. Wang, L. Q. Tan et al., "Performances and mechanisms of $\mathrm{Mg} / \mathrm{Al}$ and $\mathrm{Ca} / \mathrm{Al}$ layered double hydroxides for graphene oxide removal from aqueous solution," Chemical Engineering Journal, vol. 297, pp. 106-115, 2016.

[12] S. H. He, Z. Ding, T. D. Xia et al., "Long-term behaviour and degradation of calcareous sand under cyclic loading," Engineering Geology, vol. 276, p. 105756, 2020.

[13] X. Z. Wang, Y. Y. Jiao, R. Wang, M. J. Hu, Q. S. Meng, and F. Y. Tan, "Engineering characteristics of the calcareous sand in nansha islands, South China Sea," Engineering Geology, vol. 120, no. 1-4, pp. 40-47, 2011.

[14] A. Martin-Garin, J. P. Gaudet, L. Charlet, and X. Vitart, "A dynamic study of the sorption and the transport processes of cadmium in calcareous sandy soils," Waste Management, vol. 22, no. 2, pp. 201-207, 2002.

[15] S. Moharami and M. Jalali, "Effects of cations and anions on iron and manganese sorption and desorption capacity in calcareous soils from Iran," Environmental Earth Sciences, vol. 68, no. 3, pp. 847-858, 2013.

[16] M. Jalali, Z. Vafaee, and R. Fakhri, "Selectivity sequences of heavy metals in single and competitive systems under different 
soil/solution ratios and ph in a calcareous soil," Communications in Soil Science and Plant Analysis, vol. 51, no. 3, pp. 341-351, 2020.

[17] M. Jalali and N. A. M. Zinli, "Effects of common ions on zn sorption in some calcareous soils of western Iran," Pedosphere, vol. 22, no. 2, pp. 190-200, 2012.

[18] M. S. Akther, U. Das, S. Tahura, S. A. Prity, M. Islam, and A. H. Kabir, "Regulation of zn uptake and redox status confers zn deficiency tolerance in tomato," Scientia Horticulturae, vol. 273, article 109624, 2020.

[19] F. Dandanmozd and A. Hosseinpur, "Thermodynamic parameters of zinc sorption in some calcareous soils," Journal of American Science, vol. 6, pp. 298-304, 2010.

[20] L. E. M. Bevis and R. Hestrin, "Variation in crop zinc concentration influences estimates of dietary zn inadequacy," PLoS One, vol. 15, no. 7, article e0234770, 2020.

[21] R. Bhatt, A. Hossain, and P. Sharma, "Zinc biofortification as an innovative technology to alleviate the zinc deficiency in human health: a review," Open Agriculture, vol. 5, no. 1, pp. 176-187, 2020.

[22] S. Raeisi, H. Motaghian, and A. R. Hosseinpur, "Effect of the soil biochar aging on the sorption and desorption of $\mathrm{pb} 2+$ under competition of zn 2+ in a sandy calcareous soil," Environmental Earth Sciences, vol. 79, no. 6, pp. 1-12, 2020.

[23] H. Kang, J. Gu, G. Liu, B. Li, and W. Wang, "Performance and mechanism of layered double hydroxide to remove graphene oxide in aqueous solution," Nature Environment and Pollution Technology, vol. 20, no. 1, pp. 55-62, 2021.

[24] A. Terracciano, J. Zhang, C. Christodoulatos, F. Wu, and X. Meng, "Adsorption of $\mathrm{Ca}^{2+}$ on single layer graphene oxide," Journal of Environmental Sciences (China), vol. 57, pp. 8-14, 2017.

[25] W. Yao, J. Wang, P. Wang et al., "Synergistic coagulation of go and secondary adsorption of heavy metal ions on ca/al layered double hydroxides," Environmental Pollution, vol. 229, pp. 827-836, 2017.

[26] L. Fan, C. Luo, X. Li, F. Lu, H. Qiu, and M. Sun, "Fabrication of novel magnetic chitosan grafted with graphene oxide to enhance adsorption properties for methyl blue," Journal of Hazardous Materials, vol. 215-216, pp. 272-279, 2012.

[27] X. Guo and N. Mei, "Assessment of the toxic potential of graphene family nanomaterials," Journal of Food and Drug Analysis, vol. 22, no. 1, pp. 105-115, 2014.

[28] J. Zhou, L. Yao, Y. Wang, W. Zhao, and J. Gu, "Study on the adsorption properties of iron tailings for GO," Coatings, vol. 11, no. 7, p. 768, 2021.

[29] Z. Qi, L. Zhang, and W. Chen, "Transport of graphene oxide nanoparticles in saturated sandy soil," Environmental Science. Processes \& Impacts, vol. 16, no. 10, pp. 2268-2277, 2014.

[30] L. Li, K. K. Chang, P. Fang et al., "Highly efficient scavenging of ni(ii) by porous hexagonal boron nitride: kinetics, thermodynamics and mechanism aspects," Applied Surface Science, vol. 521, p. 146373, 2020.

[31] N. K. Mondal and S. Chakraborty, "Adsorption of cr(vi) from aqueous solution on graphene oxide (go) prepared from graphite: equilibrium, kinetic and thermodynamic studies," Applied Water Science, vol. 10, no. 2, pp. 1-10, 2020.

[32] Y. Li, Q. Li, C. Wu, X. Luo, X. Yu, and M. Chen, "The inappropriate application of the regression Langmuir $Q_{\mathrm{m}}$ for adsorption capacity comparison," Science of the Total Environment, vol. 699, article 134222, 2020.
[33] H. Sereshti, E. Zamiri Afsharian, M. Esmaeili Bidhendi, H. Rashidi Nodeh, M. Afzal Kamboh, and M. Yilmaz, "Removal of phosphate and nitrate ions aqueous using strontium magnetic graphene oxide nanocomposite: isotherms, kinetics, and thermodynamics studies," Environmental Progress \& Sustainable Energy, vol. 39, no. 2, article e13332, 2020.

[34] N. Ayawei, A. Ebelegi, and D. Wankasi, "Modelling and interpretation of adsorption isotherms," Journal of Chemistry, vol. 2017, Article ID 3039817, 11 pages, 2017.

[35] H. Shahbeig, N. Bagheri, S. A. Ghorbanian, A. Hallajisani, and S. Poorkarimi, "A new adsorption isotherm model of aqueous solutions on granular activated carbon," World Journal of Modelling and Simulation, vol. 9, pp. 243-254, 2013.

[36] N. J. Vickers, “Animal communication: when I'm calling you, will you answer too?," Current Biology, vol. 27, no. 14, pp. R713-R715, 2017.

[37] C. Cheng, M. Y. Jia, L. L. Cui, Y. Li, L. S. Xu, and X. J. Jin, "Adsorption of cr(vi) ion on tannic acid/graphene oxide composite aerogel: kinetics, equilibrium, and thermodynamics studies," Biomass Conversion and Biorefinery, pp. 1-11, 2020.

[38] A. R. de Souza, A. C. S. Guerra, M. B. de Andrade et al., "Application of graphene nanosheet oxide for atrazine adsorption in aqueous solution: synthesis, material characterization, and comprehension of the adsorption mechanism," Environmental Science and Pollution Research, vol. 28, no. 5, pp. 5731-5741, 2021.

[39] P. Zhang, G. Qian, Z. P. Xu et al., "Effective adsorption of sodium dodecylsulfate (SDS) by hydrocalumite (CaAl- LDH$\mathrm{Cl}$ ) induced by self-dissolution and re-precipitation mechanism," Journal of Colloid and Interface Science, vol. 367, no. 1, pp. 264-271, 2012.

[40] W. Wang, Y. Li, K. Yao, N. Li, A. Zhou, and C. Zhang, "Strength properties of nano-mgo and cement stabilized coastal silty clay subjected to sulfuric acid attack," Marine Georesources \& Geotechnology, vol. 38, no. 10, pp. 1177$1186,2020$.

[41] J. Wang, L. Yang, and P. C. Gu, "Synthesis and characterization of chitosan grafted molybdenum disulfide composites as an adsorbent for graphene oxide removal," Journal of Physics and Chemistry of Solids, vol. 143, p. 109471, 2020.

[42] K. Haubner, J. Murawski, P. Olk et al., "The route to functional graphene oxide," ChemPhysChem, vol. 11, no. 10, pp. 21312139, 2010.

[43] D. D. Shao, G. S. Hou, J. X. Li, T. Wen, X. M. Ren, and X. K. Wang, "PANI/GO as a super adsorbent for the selective adsorption of uranium(VI)," Chemical Engineering Journal, vol. 255, pp. 604-612, 2014.

[44] J. L. Lopes, S. Fateixa, A. C. Estrada, J. D. Gouveia, J. R. B. Gomes, and T. Trindade, "Surface-enhanced raman scattering due to a synergistic effect on zns and graphene oxide," Journal of Physical Chemistry C, vol. 124, no. 23, pp. 12742-12751, 2020.

[45] C. Weisbart, S. Raghavan, K. Muralidharan, and B. G. Potter, "Feasibility of removal of graphene oxide particles from aqueous suspensions by dc/ac electrocoagulation," Journal of Water Process Engineering, vol. 36, article 101249, 2020.

[46] J. Wang, Z. Chen, and B. Chen, “Adsorption of polycyclic aromatic hydrocarbons by graphene and graphene oxide nanosheets," Environmental Science \& Technology, vol. 48, no. 9, pp. 4817-4825, 2014.

[47] Y. Qi, M. Yang, W. Xu, S. He, and Y. Men, "Natural polysaccharides-modified graphene oxide for adsorption of 
organic dyes from aqueous solutions," Journal of Colloid and Interface Science, vol. 486, pp. 84-96, 2017.

[48] M. R. Rasouli, M. Moradi, and A. Ghalandarzadeh, "Effects of initial static shear stress orientation on cyclic behavior of calcareous sand," Marine Georesources and Geotechnology, vol. 39, pp. 554-568, 2021.

[49] J. Saeidaskari, M. Alibolandi, and A. S. Azizkandi, "Undrained monotonic and cyclic behavior of qeshm calcareous sand," Marine Georesources \& Geotechnology, vol. 39, no. 7, pp. 798-811, 2021.

[50] Y. Li, H. Yang, F. Q. Wang, and Y. Huang, "Fabrication and anti-corrosion properties of melamine-treated graphene oxide adsorbed on copper," Progress in Organic Coatings, vol. 141, p. 105564, 2020.

[51] R. Al-Gaashani, A. Najjar, Y. Zakaria, S. Mansour, and M. A. Atieh, "Xps and structural studies of high quality graphene oxide and reduced graphene oxide prepared by different chemical oxidation methods," Ceramics International, vol. 45, no. 11, pp. 14439-14448, 2019.

[52] M. Lockett, V. Sarmiento, M. Balingit, M. T. Oropeza-Guzman, and O. Vazquez-Mena, "Direct chemical conversion of continuous cvd graphene/graphite films to graphene oxide without exfoliation," Carbon, vol. 158, pp. 202-209, 2020.

[53] M. Xing, S. T. Zhuang, and J. L. Wang, "Efficient removal of cs(i) from aqueous solution using graphene oxide," Progress in Nuclear Energy, vol. 119, p. 103167, 2020.

[54] O. Akhavan, E. Ghaderi, and M. Shahsavar, "Graphene nanogrids for selective and fast osteogenic differentiation of human mesenchymal stem cells," Carbon, vol. 59, pp. 200-211, 2013.

[55] W. Wang, J. Li, and J. Hu, "Triaxial mechanical properties and micromechanism of calcareous sand modified by nanoclay and cement," Geofluids, vol. 2021, Article ID 6639602, 9 pages, 2021. 